\title{
FEDOR STANZHEVSKIY \\ TOWARDS PHENOMENOLOGICAL FOUNDATIONS \\ OF THE HERMENEUTICAL CONCEPTION \\ OF PERSONAL IDENTITY OVER TIME
}

\begin{abstract}
К ФЕНОМЕНОЛОГИЧЕСКИМ ОСНОВАНИЯМ ГЕРМЕНЕВТИЧЕСКОЙ КОНЦЕПЦИИ ЛИЧНОСТНОЙ ИДЕНТИЧНОСТИ ВО ВРЕМЕНИ

Герменевтическая концепция личностной идентичности и самопонимания - это концепция повествовательной (нарративной) идентичности. Последняя задействует герменевтический круг, который различными способами вписывается в повествовательное самопонимание. В свою очередь, самопонимание само фундировано более первичными формами сознания, связанными с телесностью.

Ключевые слова: нарративность, самость, самопонимание, самосознание, герменевтический круг, телесность.

The hermeneutical conception of personal identity and self-understanding is based on narrativity. The latter is hermeneutical in so far as it involves hermeneutic circle wich is inscribed in different ways into our self-understending. However, the narrative self is founded in the phenomenology of embodiment. There is a reciprocal connection between our narrative and embodied selves.
\end{abstract}

Keywords: narrative, self, self-understanding, self-consciousness, hermeneutic circle, embodiment.

$\mathrm{W}$

hat is the role of narratives in our life, what is their impact and scope?

Some authors take a deflationary attitude towards narratives, maintaining that their importance is exaggerated and overestimated. Others tend to explain everything by having recourse to narratives to the detriment of other components and layers of our being. In this paper I would like to take a middle stance between these two extremes. In effect, on the one hand it is hard to seriously deny the influence of narratives in our cultural and social life; on the other hand narratives do not exhaust everything that can be said about human beings. We humans are at the same time biological and social-cultural beings, our nature comprises both bios and logos. Before we become participants of the objective spirit, we are embodied creatures, and before we weave complex social and cultural concepts of our selves we are defined by our bodily

(C) Ф. СТАНЖЕВСКИЙ, 2012 
determinations. This is not to deny the reverse influence of our cultural and social dimensions on our styles of embodiment, and this circularity makes our existence more dramatic.

In this paper I pursue the task of outlining some aspects of relation that holds between the hermeneutical conception of narrative self and the phenomenology of embodiment. I agree with Dan Zahavi who considers the phenomenological conception of the self to be more fundamental with regard to the hermeneutical view, ${ }^{1}$ even though the latter obviously remains extremely influential in our everyday life (indeed all of us are practicing hermeneuts). But before suggesting some crucial points at which our embodiment underpins our narrative self-understanding, I would like to show in what sense the latter is hermeneutical. My main emphasis in the first section will therefore be on the circular character of our self-understanding, the circle in question being hermeneutical rather than vicious. In the second section I will address the issue of our embodiment which underlies some crucial aspects of our narrative comprehension.

I must apologize to the reader for excessive generality and schematism of my presentation. In fact this paper constitutes a program for further research and therefore its scope perhaps is too global, sometimes at the expense of "local" details.

\section{TOWARDS THE HERMENEUTICS OF SELF-UNDERSTANDING}

Hermeneutical conception of personal identity reveals our ways of self-understanding, rather than demonstrating any metaphysical principles of identity. According to this conception, narrative takes a crucial part in our self-understanding. Since there is no one unanimously accepted definition of narratives, I will quote one that is susceptible of satisfying most scholars owing to its generality: "at least two events must be depicted in a narrative and there must be some more or less loose, albeit non-logical relation between the events. Crucially, there is a temporal dimension in narrative". ${ }^{2}$ Narratives are ascribed various roles and forms. Here I would like to dwell on two of them - the so-called folk-psychological narratives and self-narratives that make up narrative identity. My thesis will be, firstly, that both forms are re-

1 Zahavi D. Self and Other, the limits of narrative understanding // Hutto D. Narrative and Understanding Persons. Cambridge: Cambridge University Press, 2007. P. 200.

2 Gallagher S., Hutto D. Understanding others through Primary Interaction and Narrative Practice // The Shared Mind: Perspectives on Intersubjectivity / ed. by J. Zlatev, T. Racine, C. Sinha, E. Itkonen. Amsterdam: John Benjamins, 2008. P. 17. 
lated to the hermeneutical range of problems and, secondly, that the former constitutes a basis for the development of the latter. For that purpose I am going to address the Narrative Practice Hypothesis of Daniel Hutto and narrative psychology of Jerome Bruner.

The term "folk-psychology" is often applied to our ability to understand people's actions (as well as sometimes our own actions) in terms of reasons. Reasons are constituted by propositional attitudes such as fear, hope, desire etc. which are appropriately interrelated but the most often applicable of them are beliefs and desires. The dominating theory intended to explicate folk-psychological abilities is the so-called "theory theory" which postulates the presence of an innate set of general principles and rules for "mind-reading", that is for understanding others' reasons for acting thus and so. On this view children have an innate "theory of mind" that enables them to understand people's actions by appealing to general laws including what people normally do given some combination of belief and desire. In this paper I am not going to criticize this theory at full length since my task is a more positive one - namely, to present in outline an alternative theory. However, I would like to note one important detail: the theory theory does not explain how children apply these presumed general rules to particular situations. Thus, the theory theory faces the problem which has been formulated by Aristotle under the name of phronesis; as is well known, the issue of phronesis has been adopted by Gadamer as properly hermeneutical. Using the terms of Gadamer we might also say that the theory theory implies separation of application from comprehension.

The Narrative Practice Hypothesis can elicit what remains unexplained by the theory theory. According to D. Hutto folk-psychological accounts are of narrative character and explicating reasons in terms of belief-desire interrelation has a narrative form. Hence, "folk-psychology is, in essence, a peculiar kind of narrative practice"'. On this view, our folk-psychological abilities are shaped in the course of our engagement with certain kinds of narratives in childhood, those narratives, namely, that tell about persons who act for reasons.

When children start engaging in story-telling practices supported by their care-givers, they come to understand how the elements that they mastered before (first of all, propositional attitudes) are related one to another to form reasons. Stories serve as exemplars which show them different forms and applications of folk-psychological understanding. However, children do

3 Hutto D. The Narrative Practice Hypothesis: Origins and Applications of Folk Psychology // Hutto D. Narrative and understanding persons. Cambridge: Cambridge University Press, 2007. P. 45. 
not passively receive information, on the contrary they engage in a narrative practice: first of all they identify imaginatively with protagonists, then they participate in conversations about the stories they heard, often they are encouraged to present their own explanations of actions and finally they re-enact the stories with care-givers or with their own peers. Thus, rather than learning a new set of rules they master a new skill.

Being exposed to or rather engaged in stories, children come to understand different relations that hold between various elements of the story: they get to know how desires and beliefs, hopes and fears are related to each other and what their possible connections with perceptions and emotions etc. are. As the complexity of stories grows, children learn additional factors that may influence reasons for acting, such as the protagonist's personal history, his or her character and particular circumstances in which their action is deployed. It is very important to note that rather than in an abstract way, in stories they see reasons as deployed in a concrete situation, in flesh and blood, in different contexts and against various backgrounds, and we could say that in this way they get to know some aspects of the fundamental structure of our being-inthe world. They are presented with actions and reasons in normal contexts in which these operate. Owing to this children learn some constant features of folk-psychological narratives, the norms of folk-psychology; thus, they learn also what is to be taken into account in their own stories intended to explain or justify their actions. By following numerous features that vary from story to story or within the same story they also learn what adjustments are to be made for particular situations. According to D. Hutto, encounters with folkpsychological narratives help to develop the ability to use folk-psychology in specific situations:

"The simplest person-narratives engender this kind of practical knowledge by introducing children to distinct characters and their specific background beliefs and desires, particular agendas, unique histories, personality traits and so on... [T] hese stories have precisely the right properties for familiarising children, not only with the core mentalistic framework, but also with the rudimentary norms governing its practical application. By putting examples of people acting for reasons on display, they show both how the items in the mentalistic toolkit can be used together to understand reasons in general, as it were, but also how and when these tools might be used-i.e. what to adjust for-in specific cases. They not only teach children this but they also give some hints about how to make the relevant adjustments". ${ }^{4}$

4 Ibid. P. 51. 
As we can see, folk-psychology is a skilled practice and children master at the same time both the general norms of interpreting actions and the ways to apply this skill to specific contexts. Speaking in terms of Gadamer, we could conclude that the unity of comprehension and application, disrupted by the theory theory, is restored by narrative practice hypothesis. Indeed, the knowledge that children obtain in narrative practice is not a kind of know-what, a set of general rules that need first to be understood and then applied. Rather, it is know-how which permits to understand a given particular situation in its unicity and without appeal to general principles. Would it be too daring to qualify this ability as a kind of phronesis?

No doubt, the influence of stories is overwhelming in our childhood and in adolescence; in a way it shapes our consciousness. With time its influence gets attenuated, but it is never completely effaced. The subtle relation between the general and the particular that helped us master the skill of phronesis remains instructive afterwards. Literature remains the subtle art and model of specific situations that still nourishes our capacities for phronesis.

If phronesis is acquired in a narrative way, then narrative practice can account not only for folk-psychological abilities. Or else folk-psychology should be understood in a broader way, as "a system by which people organize their experience in, knowledge about and transactions with the social world". ${ }^{5}$ In this case narrative practice teaches us to organize our experience and brings us into the culture. Indeed, even the concept of person which is so important for our self-understanding and understanding others is part of our folk-psychological tradition.

Most stories are based on dialectics between the exceptional and the extraordinary, the normal and the unusual, the canonical and the unorthodox. Indeed, according to Bruner, stories show actions deviating from the ordinary "in a comprehensible form", that is they show something which is out of the common against the background of norms. In a way narrative practice illustrates both the norms accepted in our cultures and possible violations of them. The latter are comprehensible against the backdrop of norms, but at the same time it is deviations that shed light on normality. Therefore we do not risk exaggeration if we say that narrative practice is hermeneutical in so far as it installs a kind of hermeneutical circle between general norms and specific deviations from them.

5 Bruner J. Acts of Meaning, Cambridge. Massachusetts: Harvard University Press, 1990. P. 35 . 
In Bruner's view, one of the most important roles of stories in our cultures is to exercise mediation between norms and deviations, thus mitigating the potential destructivity of the latter. This is done by narratively showing the reasons for actions that seem to be out of ordinary. Indeed, children master this function of narrative when they begin to create stories intended to justify their behavior. They learn the skill of interpretation when they realize that the way they present their story is important for justifying their actions and for adjusting them to what is normal and canonically acceptable: "Children come to recognize very early on... that what they have done or will do will be interpreted not only by the act itself but by how they tell about it". ${ }^{6}$ They also come to understand that there can be different narrative interpretations of the same events when for example their story enters in conflict with those of their peers. So we are motivated to become interpretive narrators under the impact of our cultural setting in childhood.

$$
* * *
$$

The issue of narrative identity is related to the fact that understanding occurs against some background; we understand by placing things in larger contexts. Narrativisation is one way of recourse to a larger context. Thus, according to Alasdair MacIntyre, the idea of intelligible action is primary with regard of that of action tout court, and actions become intelligible only in the context of some narrative sequence. When we face an agent's action that we cannot make sense of, we place it in some possible contexts of other actions, thereby creating some possible stories; we do this because action itself has a basically historical character. The idea of narrative identity consists in the fact that the largest narrative context for our self-understanding is our whole life presented as a story. MacIntyre understands the unity of human life as that of a narrative embodied in this life. "I am the subject of a history that is my own and no one else's, that has its own peculiar meaning".?

Paul Ricoeur considers the problem of narrative identity in terms of correlation between plot and character, the identity of character being constructed in connection with that of the plot. The identity on the level of emplotment is dominated by two opposite tendencies: the demand for concordance and inevitable discordances that threaten the identity and continuity of the plot. Concordance is the principle of order that accounts for the continuous and

6 Ibid. P. 81.

7 MacIntyre A. After Virtue. Indiana: Notre Dame, 2007. P. 218. 
ordered arrangement of facts. Discordances are constituted by reversals of fortune and turnabouts that seem to break the unity and consistency of the plot. Configuration exercises mediation between concordance and discordance; for that reason Ricoeur calls it discordant concordance and considers it to be characteristic of all narrative composition. The latter is thus a synthesis of the heterogeneous since it mediates between diverse events and the temporal unity of the story, "between the disparate components of the action - intentions, causes, and chance occurrences - and the sequence of the story; and finally, between pure succession and the unity of the temporal form, which, in extreme cases, can disrupt chronology to the point of abolishing it". ${ }^{8}$ In more general terms, it is a dialectics between the multiplicity of episodes and the unity of the plot. The same dialectics (or hermeneutic circle for that matter) of discordant concordance takes place in personal identity understood in narrative terms. My life seems continuous and ordered, but all of a sudden an event occurs that threatens this unity of sense and does not fit into my overall narrative bringing discordance into it. In order to restore the unity and meaning of my life-narrative I might rewrite my story in order to incorporate the new event into it. But anyway with time the new event becomes integrated into my story and creates some new meaning which is grasped in the light of subsequent events. The unfolding of my life-narrative makes me appropriate the new event and renders it an episode integrated into the whole of my story. This is one of the ways in which the hermeneutical circle between parts and the whole is realized in our personal stories.

We can see once again that narrative has an integrating function: it gathers together what otherwise would be disparate elements so that every element of the narrative is understood in the context of the whole.

Let me cite another example of such hermeneutical and integrative functioning, this time borrowed from psychology of personality. Dan MacAdams distinguishes three layers of personality: personality traits, contextualized concerns and narrative identity. Personality traits are relatively decontextualized and stable dispositions to behave in particular ways (in moral psychology and in ethics it is still discussed whether they have any real impact on our situated actions). They constitute what is called psychology of the stranger since they describe only rough characteristics of a person.

The second level of personality is constituted by personal concerns which comprise motive, values, personal projects and life tasks, current concerns, skills and talents etc. They represent a much more detailed and specific

8 Ricoeur P. Oneself as Another. Chicago: The University of Chicago Press, 1992. P. 141. 
domain as compared to general traits since thay are placed in different contexts of time, place or role. Many of these elements are characterized by their directedness toward future - such as motives, projects, goals and plans. Others pertain to various social roles or contextual self-images: the same person can have different self-images according to contexts, depending on persons with whom s/he speaks etc. The third level is the narrative self which is called to integrate otherwise scattered elements of personality. In the historical context we live in, which is defined as modernity, "individuals are expected to create selves that develop over time and that define who they are as similar to and different from others and as individuals whose lives manifest some degree of unity and purpose". ${ }^{9}$ Therefore narrative identity meets the need of our contemporaries for meaning, unity and purpose in their lives. Our culture induces us to integrate our different roles, values and skills into a unified self that "organizes into a meaningful temporal pattern [our] reconstructed past, perceived present and anticipated future".${ }^{10}$ This is done by constructing a story that tells my life and illustrates the continuity of my past, present and future selves.

When we look more closely at this triple division, it may seem somewhat schematic. Indeed, if personal concerns such as goals, plans and projects as well as motives are contextualized, is it not first and foremost against the background of our whole lives or parts of them? In effect, my projects and goals are on the one hand oriented towards future, on the other they are in a way motivated by my past. If there is any truth to the saying: "if you want to know where you are, you have to know how you got there", then all my personal concerns have their history which is part of my life-story. In other words, they are already narrative. And as for my personality traits, do not they influence in part the course of my life-story? And are not there in my character, along with innate traits, some acquired dispositions, hexeis, which have each its own history of acquisition and sedimentation? We could conclude paradoxically enough that before being integrated by (into) one's narrative identity or overall self-conception, traits and concerns are already understood narratively against the background of our self-story. Indeed, if someone displays hopes and projects that drastically deviate from his life story (for example, if he hastens to Borodino to fight a battle with Kutusov), we may rightly conclude that something is wrong with his mental health. The paradox will dissipate, however, if we consider that our goals, projects, plans, skills, concerns etc. are but

9 MacAdams D. Personality, Modernity and storied Self // Psychological Inquiry. 1996. N 7 (4). P. 306.

10 Ibid. P. 306. 
paradigmatic elements of what can be fully understood only syntagmatically, in the unfolding narrative. There certainly exist other elements of narrative, still more closely related to time, such as actions that we do and events that happen to us; they make our narratives move on.

Any distinction of this kind is necessarily conceptual; in real life there are circular relations between the distinguished terms that breathe life into conceptually dissected elements and confer meaning to them in the context of the whole.

In an influential article Ulric Neisser has distinguished five kinds of self-knowledge: ecological, interpersonal, extended, private and conceptual selves. It would be interesting to retrace the complex relations that hold between these levels, but for our purposes it will be enough to have a glimpse at the extended and conceptual selves. The extended self is based on memory and anticipation; it presupposes both episodic memory (remembering what I did) and script-memory (remembering what I do regularly). Life-narratives define "the self in terms of a particular series of remembered experiences". ${ }^{11}$ The conceptual self or self-concept is a cognitive model which comprises social roles, significant traits, "what things we have done in the past and likely to do in the future" 12 [italics added] etc. Neisser notes that our memory of past experiences depends not only on originally stored information, but also on what we believe now on ourselves that is on our self-conception. Therefore, our past is interpreted in the light of our actual self-conception. But Neisser does not explicitly note the inverse relation; namely, that our self-conception is in part narratively formed, that is our actual self-understanding is partially fashioned by our past experiences. The same relation holds between our self-concept and our actual experiences. The latter are understood against the backdrop of the former, but at the same time under certain conditions they may contribute to a change in self-conception. Our self-understanding is circular.

We are approaching what constitutes the essence of hermeneutics, according to Paul Ricoeur. Any hermeneutics is necessarily reflexive since comprehension always involves also self-comprehension: it is by understanding the other that I understand myself. But any reflection is also hermeneutical since we don't have transparent and immediate self-understanding; our self-comprehension needs the mediation of texts - whether those of my unconscious or those of action (Ricoeur demonstrates a semantical homology between text and action), or, finally the texts of our cultures - literature, his-

${ }_{11}$ Neisser U. Five Kinds of Self-knowledge // Philosophical Psychology. 1988. N 1 (1). P. 49.

12 Ibid. P. 54. 
tory, poetry. Now, narratives constitute an important form of texts particularly suitable to be the milieu of self-reflection. No doubt, a significant part of our lives passes without much self-reflection - many actions and indeed, interactions are culturally prescribed in forms of scripts and social roles. Reflection is needed when something goes wrong or changes in our narrative: when, for example we feel guilty because of an action of ours that does not fit the whole of our self-narrative or our self-conception, or when we hear something new and revelatory on our account, or else when we face a difficult and important choice. What we do when we reflect in these cases is not so much deep introspection as rather narrativization. We try to retrace events, actions and words shaping them into what we consider to be the right story and thus we make up a narrative in order to justify ourselves (rationalization is a particularly narrative mechanism of defence) or to put up with an unpleasant truth and modify our self-concept; when making a choice, we weigh up different possibilities by imagining possible narrative developments. It is in this way that reflection promotes (or hinders) our self-understanding and affects our notion of who we are.

Understood narratively, reflection is not quite different from folk-psychological exercise; in effect, it seems to have the same origin: before we learnt how to make account of our actions to ourselves, we had to make such accounts to others. In fact, self-reflection and self-criticism seem to be an internalized dialogue which is carried out by means of narratives (we could understand it better if we addressed the issue of inner speech in Vygotsky: the children's so called "egocentric" speech that, when internalized, becomes inner speech, is in fact always other-oriented). When we put ourselves to critical revision, it is the internalized voice of the other that speaks in us - whether that of particular significant others or that of the society in the whole: one of the paramount functions of narratives is to integrate us into the society and whether we want it or not, when we reflect we use criteria produced by our society. We have learnt many of them when we engaged in narratives in childhood and it was then that otherness was firmly installed in our minds.

But if even reflection which used to be considered as intimately mine, is in fact permeated with the other, what then remains for me? Am I but a passive carrier or transmitter of tradition? Not quite, since hermeneutical thought does not understand tradition as a purely passive affair; I may creatively rethink or remodel it, I can use it consciously and finally co-author my life with the other, but I will never be the only author of my life. Even if I want to radically change my understanding and self-understanding revolting against tradition, it will always remain my starting point. However, I am not a robot 
that realizes a built-in program: in fact, novel situations I have to cope with when I reflect or when I exercise my narrative capacity for understanding are not programmed and demand the exercise of my phronetic abilities; in fact it is difficult to imagine a domain of experience more specifically human than phronesis. It is always creative.

In reflection I appropriate my attributes or my past actions and thoughts, I incorporate them (or reject and repress) into the unity and continuity of my life and in this way I constitute my identity or my self-conception. On the other hand, my identity, "my sense of who I am guides my actions and deliberations and projects my identity into the future". ${ }^{13}$ Once again we deal with a circle which makes me advance and thus is not vicious but hermeneutical.

Importantly, when I reflect on myself, I am at the same time the subject and the object of reflection; I look at my (third-personal) self from my firstperson perspective. Who is then the one who reflects? In the famous fragment of the "Blue book" Wittgenstein says: "When I said, from my heart, that only I see, I was also inclined to say that by "I" I didn't really mean L. W., although for the benefit of my fellow men I might say "It is now L. W. who really sees" though this is not what I really mean. I could almost say that by "I" I mean something which just now inhabits L. W., something which the others can't see $^{14}$ ". What was then the difference for Wittgenstein between these two expressions, and what makes difference for John Doe to say "I see" or "John sees"? Wittgenstein continues: "There are two different cases in the use of the word "I" (or "my") which I might call "the use as object" and "the use as subject". Examples of the first kind of use are these: "My arm is broken", "I have grown six inches", "I have a bump on my forehead", "The wind blows my hair about". Examples of the second kind are: "I see so-and-so", "I hear soand-so", "I try to lift my arm", " $I$ think it will rain", "I have toothache". This division between the two uses of the word "I" and "me" is related with the issue of immunity to error through misidentification: I can be in error when I use "me" as object, but I cannot wrongly identify myself as subject. I can mistakenly attribute a trait or an action to myself, but I cannot be in error as for the fact that it is me who makes the attribution.

But this distinction does not settle the question about who is the subject of reflection or attribution. We could make a first step towards clarification together with Dan McAdams. Drawing on William James, he distinguishes

13 Atkins $K$. Narrative identity and embodied continuity // Practical Identity and Narrative Agency. Routledge, 2008. P. 86.

14 Wittgenstein L. The Blue Book. Blackwell, 1958. P. 66. 
two aspects of self - the I and the Me. ${ }^{15}$ These are not understood as two entities; rather, the I is a process, and the Me is its product. The I is understood as a verb, a sort of "selfing", which is a process of making a self out of experience. "To self is to apprehend one's actions, feelings and thoughts as mine... to grasp phenomenal experience as belonging to me". ${ }^{16}$ The "Me" is a product of selfing, it embraces personal traits, concerns and life stories. They are appropriated as mine, synthesized and reflected upon by means of the process of selfing. The latter binds together different aspects of Me over time. In this sense the process of selfing is the subject whose object is narrative identity. This picture permits to understand both the subject of reflection or narrative attribution and its object in an integrated way; it does not postulate any mystical entity over and above the process of selfing which is no other than the stream of consciousness. However, this description remains somewhat abstract and it needs to be fleshed out; this can be done with help of the phenomenology of embodiment.

\section{TOWARDS PHENOMENOLOGICAL GROUND OF OUR SELF-UNDERSTANDING}

In this section I would like to briefly outline the ways in which our embodied condition underlies our hermeneutical self-understanding. The first thing to be demonstrated is that our narrative self-consciousness is based on a more fundamental kind of self-awareness.

According to the neurobiologist Antonio Damasio consciousness is always accompanied by self-consciousness; the latter being a feeling what happens when we perceive or apprehend. This feeling is what marks our perceptions as ours, it is a "sense of self in the act of knowing". ${ }^{17}$ It reveals "some presence of me" in relationship with the objects of my perception or apprehension; it provides me with the feeling that it is me who sees, hears, touches etc. This presence of me in my experiences is not reflexive, it is "quiet and subtle". This sense of me accompanies all my experiences and actions. Damasio calls this kind of consciousness "core consciousness", which is my self-awareness here and now. This core consciousness underpins a more complex kind of self-consciousness, extended consciousness which accounts for our identity and personhood and places me in culture and society. It has obviously a narrative structure, and it makes me aware of my lived past and anticipated future

15 MacAdams D. Personality, Modernity and storied Self. P. 302-303.

16 Ibid.

17 Damasio A. The Feeling of What happens. New York, 1999. P. 25. 
along with the here and now of my present situation. While core consciousness may be said to be tied with short-term working memory, extended consciousness is related to episodic memory. Importantly enough, while impaired extended consciousness leaves core consciousness intact, impairments of the latter provoke also the disruption of extended consciousness. This suggests that extended consciousness is founded on core consciousness which is more basic with regard to the former. Damasio notes that core consciousness is correlated with the core self, while extended consciousness is connected with the autobiographical self.

Core consciousness seems to be identical with what Dan Zahavi, drawing on the phenomenological tradition calls pre-reflective self-awareness. Pre-reflective self-awareness enables us to be conscious of our experiences in their first-personal mode of givenness, or in other words it provides us with first-personal access to everything we experience. Owing to it our various experiences which otherwise would be disparate become united by one common quality, their mineness. I feel an experience as mine immediately and non-reflexively, its mineness being felt "as a subtle background presence". ${ }^{18}$ Zahavi correlates this pre-reflective sense of mineness with "a minimal or core self". However, this self is not an entity which would have a separate existence from our stream of consciousness, it is just the feature of first-personal givenness of our experiences. This self, being inseparable from the stream of consciousness is a good candidate for the processual "I" of selfing that objectifies and appropriates the narrative "me" as well as for the subject who thematizes himself in reflection; for there to be anything or anybody to reflect on, first there needs to be prereflective self-awareness. Indeed, prereflective self-awareness constitutes the most intimate aspect of the life of subject, but it shows the subject as already immersed in the world, engaged in situations, since it quietly accompanies his intentional consciousness.

Pre-reflective self-awareness is embodied, as we can see if we address the issue of body schema. ${ }^{19}$ Body schema is a system of sensory-motor processes that regulate our postures and movement; it is holistic and sensitive to our environment. It is body schema that permits me not to consciously control my bodily movements when my intention is oriented to an object or situation. Body schema is "prenoetic", it leaves body transparent and subordinates it to larger intentional activities.

${ }_{18}$ Zahavi D. Subjectivity and Selfhood. Cambridge; Massachusetts: The MIT Press, 2005. P. 124.

19 Gallagher S. How the body shapes the mind. New York: Oxford University Press, 2005. 
Body schema is manifested in newborns in the phenomenon of neonate imitation. Newborn infants can imitate facial gestures of adults thus responding to stimuli in an appropriate way, their gestures matching those of their caregivers. This phenomenon suggests the presence of an innate body schema that already functions at birth. It enables collaboration between the visual perception of the other by the infant and its own proprioception. It is this collaboration that is responsible for natural coupling between self and other. Gallagher notes that the infant perceives its own embodied possibilities in the face of the other and most probably it is this perception of the other's movement that "triggers my own proprioceptive awareness". Therefore my self-consciousness at the very beginning, in its most primitive and fundamental form is linked with the other and in a way originates in the other's gaze and gestures. In effect, according to Gallagher "body schemas working systematically with proprioceptive awareness, constitute a proprioceptive self that is always already coupled with the other". ${ }^{20}$ In Gallagher's view, the phenomenon of neonate imitation suggests the existence of a primary sort of self, proprioceptive self as well as the presence of some level of rudimentary differentiation between self and non-self.

Consequently, our primary and most fundamental sense of self, the basis of our first-person perspective is embodied, since it is closely related with body schema. Body schema also accounts for our primary intersubjectivity and in a way highlights its primacy over our subjectivity. Therefore our being exposed in childhood to others in narratives that gradually fashion and nourish our narrative self is itself rooted in our more primitive dependence on others due to our embodied condition - in that very dependence or coupling that Merleau-Ponty called intercorporeity. Once again a phenomenological concept (in the occurrence that of body schema) proves to have a founding role with regard to our narrative constitution. Others are already present in our narrative selves and in our reflection because otherness from the very beginning takes an inalienable part in our embodied self.

According to Gallagher who draws on Trevarthen in this matter, the bond that binds me with the other undergoes development as the infant grows. ${ }^{21}$ Thus, the stage of primary intersubjectivity is characterized by the infants being able to grasp meaning in others' gestures and actions as well as to understands emotions and disposals of others with regard to them. This

20 Ibid. P. 81.

${ }^{21}$ Gallagher S., Hutto D. Understanding others through Primary Interaction and Narrative Practice. P. 20-26. 
perception is direct and immediate rather than reflexive or inferential, and it does not wither giving way to ulterior stages - rather, it characterizes our primitive way of dealing with others in the course of our entire lives.

Secondary intersubjectivity is more complex; it comprises not only perceptions of others' emotions or dispositions but also those of their relations to things in the world. At this stage children grasp others' intentions with regard to surrounding objects, they begin to understand how others interact with the world. The phenomenon of joint attention permits children to share a situation or an object with the other, and it lays foundations for further sharing of the world with others. Children begin to grasp the meaning of a situation, of pragmatic contexts or contexts of actions. This stage is extremely important and it is the condition of possibility of posterior narrative interpretations of situations, of people acting in different contexts and settings. In a way the bodily phenomenon of joint attention underlies our more mature folk-psychological abilities and thus enables us to become cultural and social beings and to have the ability of narrative (self)-interpretation.

The distinction between body image and body schema can elicit our capacities for reflection. Body image is a "system of perceptions, attitudes, beliefs and dispositions pertaining to one's own body". ${ }^{22}$ Therefore, unlike purely "subjective" body schema, body image pertains to our objectifying attitude towards our body. Kim Atkins, drawing on Gallagher, shows that body schema and body image account for our having first-person perspective and our being third-personal entities respectively. ${ }^{23}$ Therefore it is our body that makes possible this living and dynamical relation between first-person and third-person perspectives which underlies my ability to look from the firstperson perspective at my third-personal characteristics, to make myself an object of my own reflection and to narratively constitute my "Me".

Concluding this general and schematic review of the phenomenological foundations of our hermeneutical self-conception, we cannot omit the complex and dramatic issue of time. For reasons of space I will have to confine myself to a very brief outline of this problem.

The phenomenological conception of time is clearly fundamental with regard to the narrative view. ${ }^{24}$ Recollection and expectation (which constitute

22 Gallagher S. How the Body shapes the Mind. P. 37.

23 Atkins K. Narrative identity and embodied continuity // Practical Identity and Narrative Agency. Routledge, 2008. Of course body image is influenced also by others who can perceive my body, and in part it must be shaped under their impact, exactly as my conceptual self is.

24 Thompson E. Mind in Life. Cambridge; Massachusetts: Harvard University Press, 2007. P. 320 . 
my narratively constructed ways of remembering the past and anticipating the future) presuppose the functioning of retention and protention. Indeed, in Husserl's view recollection and expectation stand to retention and protention respectively as secondary memory and anticipation stand to primary ones, the former being representational while the latter are presentational. Recollection and expectation are deliberate and reflexive acts, whereas retention and protention are involuntary and pre-noetic (pre-reflexive) processes operating to make our experiences unified and continuous.

Shaun Gallagher argues in a convincing way that the triple structure of time (retention — primary impression — protention) characterizes our body schema, which is therefore temporally structured. For example, "motor action itself, in its prenoetic body-schematic performance, has the same tacit and auto-affective structure that involves the retention of previous postures, and the anticipation of future action". ${ }^{25}$ Here we cannot pursue this extremely important issue, but we can draw the conclusion that our time consciousness is deeply rooted in our embodiment.

\section{Conclusion}

In this paper I have outlined a program of research aimed at demonstrating the phenomenological aspects of embodiment underlying the hermeneutical conception of narrative self-understanding. I have distinguished in outline several points of intersection. Thus we have seen that our capacity to engage in folk-psychological narratives which brings us into culture and society is ontogenetically founded in the embodied mechanism of joint attention which constitutes an initial step towards understanding agents as acting in settings, contexts ans situations. This capacity originates in body schema.

Then we have seen that our extended or narrative self is founded in a more embodied minimal or core self characterized by pre-reflective selfconsciousness which is also related to body schema. Prereflective self-consciousness accompanying any intentional consciousnessis is the low-level embodied basis of the hermeneutical principle according to which any highlevel understanding is at the same time self-understanding.

The distinction between body schema and body image as basis for firspersonal perspective and third-personal self-objectification founds the possibility of reflection; phenomenology of embodiment provides us with an insight into the nature of the reflecting subject: it is not separate from our stream

25 Gallagher S. How the Body shapes the Mind. P. 204. 
of consciousness, in fact it coincides with the minimal self; besides that it is a kind of subject which is always immersed in the world. We might say that it is a phenomenological subject that appropriates hermeneutical reflection.

Finally, we have mentioned the fact that narrative time with its possibilities of recollection and expectation is itself founded in phenomenological time structured as retention - primary impression - protention. This timestructure is itself inseparable from our embodiment; in fact it characterizes our body schema.

Therefore our cultural and biological aspects do not exist apart from each other; on the contrary, they exercise mutual influence on each other. We have outlined the founding role of the body with regard to our self-understanding. The reverse influence of our social and cultural self-understanding on our bodily determinations is a topic for considerable research; however, it is clear that our embodied core self cannot but be modified under the impact of our cultural extended self. The style of my stream of experience given to me in the first-person perspective is colored by my cultural and social determinants that define my narrative being. Therefore my narrative "Me" has also some subtle impact on my selfing "I", it affects the mode or shade of the process of selfing and nuances my unique perspective. Therefore there exists a kind of circular link between the subject and the object of reflection, the very circle that renders our being itself hermeneutical.

\section{Author}

Stanzhevskiy Fedor - research worker of the Centre for Phenomenology and Hermeneutics, Faculty of Philosophy, St.-Petersburg State University.

СТАНЖЕВСКИй ФЕдоР — научный сотрудник Центра феноменологии и герменевтики философского факультета СПбГУ.

E-mail: stanzh@mail.ru 